\title{
Noções do trabalho corporal na formação do(a) artista-docente: há espaço para as diversidades na pedagogia do Teatro?
}

Concepts of corporal work in the training of the artist-teacher: is there space for diversities in Theater education?

Marcia Berselli ${ }^{1}$

Diego de Medeiros Pereira ${ }^{2}$ 


\section{Resumo}

O artigo visa a discutir questões relativas ao trabalho corporal na formação de artistas-docentes das artes cênicas, a partir das experiências dos autores como docentes das disciplinas de Expressão Corporal em um curso de Licenciatura em Teatro. A formação desse profissional é problematizada, destacando a importância das diversidades de ser, (re)existir e se expressar no mundo, tensionando o contexto atual do ensino de teatro com pressupostos observados na cena contemporânea. Autores como Fortin (2011), Lehmann (2011) e Le Breton (2009) fundamentam as discussões apresentadas. A responsabilidade sobre a formação do licenciado que atuará em diferentes contextos é destacada, indicando à importância da reflexão sobre o tema nos processos de ensino-aprendizagem na universidade.

Palavras-chave: Trabalho corporal; corpo; artista-docente; pedagogias do teatro; diversidades

\section{Abstract}

The article aims to discuss issues related to corporal work in the professional formation in theater education area, from the experiences of the authors as professors of the disciplines of Corporal Expression in a theater teacher education program. The formation of this professional is problematized, highlighting the importance of the diversity of being, (re) existing and expressing themselves in the world, stressing the current context of theater teaching with assumptions observed in the contemporary scene. Authors such as Fortin (2011), Lehmann (2011) and Le Breton (2009) base the discussions presented. The responsibility for the formation of the teacher that will act in different contexts is highlighted, indicating the importance of the reflection on the subject in the teaching-learning processes in the university.

Keywords: Corporal work; body; artist-teacher; theater education; diversities

\footnotetext{
Profa. Universidade Federal de Santa Maria (UFSM). Doutoranda no Programa de Pós-Graduação em Artes Cênicas da Universidade Federal do Rio Grande do Sul (UFRGS). Líder do Grupo de Pesquisa Teatro Flexível: práticas cênicas e acessibilidade (CNPq/UFSM). bersellimarcia@gmail.com

2 Prof. Dr. Universidade do Estado de Santa Catarina (UDESC). Líder do Grupo de Estudos sobre Teatro e Infâncias (GETIs/CNPq) e do Laboratório de Criação (LACRI/CNPq). Ator, dançarino e encenador teatral. diego_ccac@hotmail.com
} 
Ao tratarmos do profissional da cena, em especial daquele que se expõe ao olhar do outro - atriz, ator, performer - é impossível pensar os aspectos formativos da função por eles exercida sem destacar o trabalho corporal. Por conseguinte, em qualquer prática pedagógica em artes cênicas - seja no âmbito da Educação Básica, do Ensino Superior ou de cursos livres - é imprescindível que levemos em consideração as práticas corporais como elemento intrínseco à apropriação da linguagem teatral.

Ainda que as práticas da atuação, entendidas como metodologias possíveis ao trabalho do ator/atriz, destacaram-se na história dos expoentes da cena ocidental, elas dificilmente estavam desconectadas de um trabalho corporal específico. É o caso de Stanislavski (1863-1938), para quem a profissão do ator supunha uma ampla preparação que envolvia aulas de esgrima à um intenso trabalho diário, assim como de Meyerhold (1874-1940), aluno de Stanislavski, para quem as práticas desenvolvidas no Teatro de Arte de Moscou não alcançaram êxito, levando-o a uma investigação particular que vai indicar a outro trabalho corporal específico, nomeado Biomecânica. Poderíamos lembrar outro contemporâneo de ambos diretores citados, Taírov (1885-1950), o qual exigia um trabalho ainda mais exaustivo de modo a negar um ator diletante em busca do super ator - representado pela tríade ator-acrobata-bailarino.

Para além dos expoentes russos mencionados, poderíamos seguir elencando diretores e pedagogos que, ao investigarem o trabalho da atuação, colocaram especial atenção sobre o corpo do intérprete. Um exemplo importante é o brasileiro Augusto Boal (1931-2009). Em suas proposições acerca da Poética do Oprimido, Boal indica que o trabalho deveria "[...] começar pelo próprio corpo das pessoas interessadas em participar da experiência" (Boal, 1980, p. 133), e complementa:

Podemos mesmo afirmar que a primeira palavra do vocabulário teatral é o corpo humano. Por isso, para que se possa dominar os meios de produção teatral, deve-se primeiramente conhecer o próprio corpo, para poder depois torná-lo mais expressivo. (Boal, 1980, p.131)

Na fase de seu trabalho em que a abordagem está relacionada a transformar o espectador em espect-ator, Boal se preocupa em tornar conscientes as estruturas musculares e padrões corporais que, segundo o teatrólogo, estão diretamente relacionados aos modos de vida de cada pessoa, às suas profissões, ao status social (Boal, 1980). Anteriormente, o trabalho de Boal com os atores do Teatro de Arena também iniciava sob a premissa de sensibilizar os corpos muscularmente automatizados e mecanizados (Boal, 2012). Um treino específico, o domínio dos movimentos, o conhecimento da estrutura física podem ser destacados, assim, como princípios do trabalho daquele que oferece seu corpo ao olhar do outro. É possível afirmar que o corpo é, de início, foco das práticas formativas no campo das artes cênicas.

Ao tratamos de uma proposta de ensino-aprendizagem em teatro o reconhecimento das capacidades expressivas do corpo, a ampliação dessa expressividade, o uso do gesto/ação de forma consciente, a elaboração corporal de um discurso, a exploração das competências corporais se apresentam como objetivos a serem alcançados para um efetivo trabalho de apreensão dessa linguagem. 
Cabe destacar, entretanto, que quando falamos em corpo uma série de significados emergem, sendo que tais entendimentos vão incidir, diretamente, sobre as práticas desenvolvidas. Conforme aponta Sylvie Fortin, “[...] nossas representações do corpo vêm dos discursos sociais dominantes ou alternativos [...] aos quais fomos expostos durante a vida" (2011, p. 28). Nesse sentido, valores e comportamentos são adquiridos e assimilados consciente e inconscientemente, sendo reproduzidos ou questionados quando o corpo se coloca como centro de encontros e processos, tais como ocorre nas práticas cênicas, área que, por sua natureza, implica a exposição corporal. Lehmann corrobora com a ideia ao apontar que: "Em nenhuma outra forma de arte o corpo humano ocupa uma posição tão central quanto no teatro, com sua realidade vulnerável, brutal, erótica ou 'sagrada'" (Lehmann, 2011, p. 331).

Pensar processos de ensino-aprendizagem nessa área implica recuperar o histórico da formação no campo do teatro, no contexto brasileiro, fortemente marcada pela explosão da Antropologia Teatral (Barba; Savarese, 1995) nos anos de 1980. Formatada por Eugênio Barba, tal disciplina está calcada na ideia de treinamento corporal que tem como características o virtuosismo e o alto nível de rendimento dos artistas que têm seu processo mediado por um mestre ${ }^{3}$.

Como premissa, tais práticas se centram no máximo rendimento corporal e na formatação de um corpo apto a qualquer movimento, disponível a responder a qualquer demanda imposta pela cena, pelo jogo entre os colegas ou, ainda, pelo diretor. Sem questionarmos o valor da prática corporal, que dentro de suas especificidades desenvolve competências necessárias a determinadas formas de atuação, é necessário indagarmos sobre o quanto tal campo disciplinar, em geral, está diretamente conectado com uma estética da cena e com um pensamento sobre o teatro próprio de determinados períodos e contextos histórico-culturais. Ou seja, o quanto estão em jogo princípios éticos, estéticos e políticos que talvez atritem com perspectivas mais amplas sobre o campo teatral, tais as expostas pela cena contemporânea e os discursos que primam pela diversidade.

$\mathrm{Na}$ formação dos artistas-docentes, entretanto, parece-nos importante indagar se esses são estimulados a refletir sobre os princípios que regem as proposições de trabalhos com o corpo. Como futuros artistas-professores de teatro, o quanto lhes é dado a conhecer sobre os aspectos fundantes das práticas para além dos exercícios realizados? Quais espaços de criação são, de fato, propiciados em práticas que primam pela reprodução de técnicas e produção de discursos que, em geral, não dizem respeito aos corpos que os apresentam/representam?

É preciso reconhecer que em nossa sociedade, visual e midiática, as representações corporais dominantes apontam para uma construção social do corpo centrada em uma noção de beleza que, de modo geral, tem seu padrão representado pelos corpos brancos, cisgêneros, magros, fortes (com grupos musculares específicos que devem ser ressaltados para homens e mulheres), sendo que os "desvios" a esse padrão geram frustrações, sentimentos de inadequação, discriminação e, em alguns casos, rejeição.

\footnotetext{
3 É preciso destacar que, em geral, as relações mestre/discípulo indicam uma pedagogia autoritária na qual o bem-estar do estudante/aprendiz é relegado a segundo plano em benefício de uma reprodução estética do movimento que represente os ideais do mestre, ideais esses que se estenderão representados pelos discípulos.
} 
O corpo é objeto de constante preocupação. Trata-se de satisfazer a mínima característica social fundada na sedução, quer dizer, no olhar dos outros. O homem mantém com o corpo, visto como seu melhor trunfo, uma relação de terna proteção, extremamente maternal, do qual retira um benefício ao mesmo tempo narcíseo e social, pois sabe que, em certos meios, é a partir dele que são estabelecidos os julgamentos dos outros (Le Breton, 2009, p. 78).

Temos, assim, modelos corporais dados como "dentro" e outros "fora" das normas aceitáveis. Tal norma, no entanto, é específica de determinada sociedade, posta em operação a partir da manutenção de discursos que formam o corpo e informam sobre ele. Para o sociólogo David Le Breton o corpo é socialmente construído, “[...] as representações do corpo são representações da pessoa. [...] O corpo é uma falsa evidência, não é um dado inequívoco, mas o efeito de uma elaboração social e cultural" (2009, p. 26). Os repertórios e vivências que nos constituem marcam, assim, os significados que atribuímos ao corpo, pautando nosso imaginário acerca do normal, do aceitável e do desejável. Não são concepções dadas, mas, sim, naturalizadas, introjetadas, construídas em nossa trajetória na sociedade.

Se tais marcas corporais são uma constante na sociedade contemporânea, na qual a aparência se torna um capital (Le Breton, 2009), o teatro, questionador por natureza, pareceria, à primeira vista, um espaço de contraposição à essa perspectiva.

A concepção cultural sobre o que é "o" corpo está sujeita a flutuações "dramáticas', e o teatro articula e reflete essas concepções. Ele representa corpos e ao mesmo tempo os têm como seu principal material de significação. Mas o corpo teatral não se contenta com essa função: ele é um valor sui generis. Não obstante, antes da modernidade a realidade física do corpo permaneceu geralmente incidental no teatro. Disciplinado, treinado e moldado para a função da significação, o corpo não era nem um problema nem um tema autônomo do teatro dramático, no qual permaneceu sobretudo como uma espécie de "subentendido". Isso não é de surpreender, já que o drama se constituiu essencialmente em função da abstração da densidade do material, da concentração "dramática" em conflitos espirituais - em contraposição à predileção épica pelo detalhe concreto. (Lehmann, 2011, p. 332, grifos do autor).

Ainda que a ideia de apagamento do corpo em função do personagem siga presente em formas de atuação dramáticas, especialmente as realistas, é necessário reconhecer que a cena contemporânea questiona imposições corporais e normas estéticas. Faz-se igualmente necessário, porém, perguntar-mo-nos se o campo da formação em teatro segue pelo mesmo caminho.

Ao discutirmos os espaços de ensino-aprendizagem, caberia uma breve reflexão sobre os padrões corporais que seguem se fazendo ver nos espaços institucionais. Quem foram nossos colegas de graduação? Quantos professores negros ou trans participaram de nosso processo formativo? Havia elevadores e rampas nos prédios onde tiveram lugar nossas aulas de teatro? E hoje, quem são nossos colegas nas escolas, universidades, grupos de teatro? Há diversidade no grupo de estudantes e professores? As diversidades são parte da agenda das instituições de ensino - presente no cotidiano de professores e estudantes - para além das exigências legais fixadas em documentos? 
Parece não caber mais nos processos formativos em teatro a relação "mestre e discípulo" em prol de uma formatação estética que invisibiliza as diversidades. As práticas que buscam um determinado padrão corporal para a cena apagam os corpos dissonantes da estética desejada pelo professor/condutor do processo. Como aponta Miller "[...] o corpo da cena contemporânea está com novas luzes, mas o corpo da sala de aula contemporânea pode muitas vezes não ser iluminado pelos mesmos holofotes inovadores" (2012, p. 57). Se entendemos o teatro como provocador e questionador das normas e condutas sociais e culturais impostas, parece-nos necessário o fortalecimento e afirmação dos sujeitos envolvidos no fazer teatral a partir de seus próprios discursos e construções identitárias.

Nesse sentido, como docentes do Ensino Superior, colaboradores na formação de futuros professores de teatro, compreendemos que existem, ao menos, dois níveis de trabalho a serem levados em consideração na elaboração das ações pedagógicas propostas em componentes curriculares relacionados às práticas corporais nos cursos de graduação.

O primeiro diria respeito ao trabalho do licenciando sobre si; a compreensão do seu corpo, seja como forma de se (re)conhecer como um ser que existe no espaço em diferentes dimensões (físicas, sensoriais, psicológicas, emocionais), com suas limitações e possibilidades a serem investigadas, respeitadas e, possivelmente, ampliadas, ou ainda como material para sua formação como artista da cena que utilizará esse "instrumento" para a elaboração de um discurso artístico.

Um segundo nível de trabalho, que nos parece necessário na formação desse estudante, é buscar dimensionar em que medida ele poderá se utilizar desses saberes nos processos de ensino-aprendizagem que instaurará com educandos nas escolas, os quais não desejam ser atores e muitos, sequer, relacionam-se de modo consciente com seus corpos, visto que, a própria escola é uma das instituições responsáveis pela castração do movimento. Como aponta Jorosky:

[...] há grandes preconceitos contra o movimento, pois embora conscientes de que é através do corpo que o indivíduo se expressa, quando chegam aos bancos escolares os movimentos corporais ficam restritos a momentos apenas nas aulas de educação física e ao horário do recreio. Para o professor desenvolver conteúdos, os alunos devem permanecer sentados em suas carteiras em silêncio, prestar atenção, e sempre olhar para frente. (2010, p. 156)

Diante desse contexto inicial, buscaremos refletir sobre os modos como temos proposto o trabalho corporal nas disciplinas relativas à essa área na formação de licenciados em teatro na Universidade Federal de Santa Maria (UFSM), no interior do Rio Grande do Sul. Qual corpo essas práticas "exigem"? Quais habilidades são esperadas? Quem são os habilitados? Para além da mímese, quais informações esses sujeitos nos trazem à sala de aula? Como alterar algumas práticas corporais arraigadas e instigar os estudantes a pensarem as relações entre corpo e estética? 


\section{Corpos na formação do Licenciado em Teatro}

Atravessados por uma multiplicidade de leituras e representações do referencial corpo, como professores e formadores de professores precisamos nos questionar que corpo é esse que chega na sala de aula? O que o atravessa, o que o constitui como sujeito singular? Como ajustar nossas metodologias de trabalho de modo a desenvolver conteúdos específicos sem restringir a participação nem negar a presença das singularidades? Talvez, para responder a essas questões, seja necessário olhar para os objetivos das práticas corporais nos currículos da área de Artes Cênicas. O que se espera que o estudante desenvolva como conhecimentos e competências após a aproximação aos conteúdos da área de corpo?

Tomando como exemplo o currículo vigente no Curso de Licenciatura em Teatro da Universidade Federal de Santa Maria, destacamos que as súmulas das três disciplinas intituladas Expressão Corporal e Vocal I, II e III, alocadas no primeiro, segundo e terceiro semestres do curso, respectivamente, indicam como objetivos a consciência corporal buscando o desenvolvimento da capacidade expressiva e criativa do estudante, além do conhecimento sobre as qualidades do movimento corporal e da produção vocal ${ }^{4}$.

De modo geral, as ementas estão centradas no desenvolvimento de competências relativas ao trabalho do ator; o corpo como instrumento da criação teatral, a presença psicofísica do ator, a relação com o texto teatral, são alguns dos conteúdos elencados. Assim, é o trabalho articulado entre os conteúdos propostos e a abordagem metodológica do professor que pode provocar o estudante, após a compreensão das práticas em sua vivência, a fazer relações entre essas e os contextos de ensino-aprendizagem em que ele atuará. Para tanto, entendemos que o estímulo à capacidade de pensamento crítico, atrelada à prática, é fundamental.

Por se tratarem de práticas que exigem a exposição contínua do corpo, também pode ser a reflexão uma aliada no entendimento das implicações que a sociedade da imagem faz reverberar na aula de expressão corporal. Parece necessário que os estudantes sejam convocados a refletir sobre a "necessidade" constante de parecerem bonitos, de arrumarem a roupa, o cabelo, de se maquiarem quando a aula em questão pressupõe suor e cansaço. De onde vem tal necessidade e o quanto estamos conscientes dela no dia a dia? O quanto ela implica na vergonha ou desconforto em realizar alguns exercícios junto aos demais colegas, sob o medo de "parecer feio"? Qual o impacto desse suposto olhar julgador na aula que busca desenvolver a expressividade corporal?

Parece ainda haver uma hegemonia de padrões de "corpo para a cena" que tenta enquadrar as particularidades e diversidades corporais em uma determinada caixa em que elas não cabem ou não querem estar. Como instigar os estudantes de teatro a saírem do jogo de reprodução/representação de "tipos" e ocuparem um espaço de criação - um teatro (ou os teatros) a partir dos corpos?

4 Disponíveis em: <https://portal.ufsm.br/ementario/curso.html?idCurso=1187>. Acesso em: 29 out. 2018. 
Atentos a essas perspectivas buscamos estruturar as disciplinas Expressão Corporal e Vocal I e III, as quais são ministradas pelos dois professores autores do presente artigo e que serão, na sequência, brevemente abordadas de modo a ampliar a reflexão aqui tecida ${ }^{5}$. Na disciplina Expressão Corporal e Vocal I desenvolvemos o trabalho, com os estudantes que estão chegando na universidade, a partir de abordagens somáticas do movimento. A súmula da disciplina, assim, destaca o trabalho das práticas visando à consciência e sensibilização corporal. O conteúdo da disciplina aborda o conhecimento e organização do corpo através da percepção de forma, volume e estrutura óssea; a sensibilização por meio de exercícios de peso, apoio, equilíbrio e contato; o relaxamento e harmonização do tônus corporal além de alongamento e flexibilidade.

Primando pelo reconhecimento sutil de sua própria estrutura, a frente da disciplina estamos cientes de que, a cada ano, os estudantes chegam na universidade atravessados por uma cultura que, dependente da tecnologia, coloca-nos em posições de inércia ou pouco movimento corporal para desempenhar nossas atividades cotidianas. Desse modo, articulamos as práticas com a atenção para que nenhuma etapa seja ultrapassada, dilatando o tempo dedicado a cada exercício. Toda a prática desenvolvida tem como base que o estudante possa ir reconhecendo suas construções corporais atreladas às construções sociais. Fundamentam o conteúdo as perspectivas sociológicas sobre o corpo de David Le Breton (2009), além do método Feldenkrais (1977) e princípios do Contato Improvisação (Paxton, 1997).

Feldenkrais, criador da prática somática que leva seu nome, desenvolveu dois métodos de proposição da técnica, sendo um deles nomeado Consciência corporal pelo movimento, no qual a prática se centra no autoconhecimento corporal e no reconhecimento de nossos hábitos, sendo que, para Feldenkrais: "Cada um de nós fala, se move, pensa e sente de modos diferentes, de acordo com a imagem que tenha construído de si mesmo com o passar dos anos. Para mudar nosso modo de ação, devemos mudar a imagem própria que está dentro de nós" (1977, p. 27).

As práticas escolhidas têm como característica a abertura a corpos com diferentes organizações e estruturas, acolhendo os estudantes em suas mais diversas possibilidades e limitações corporais. $O$ interesse está centrado no reconhecimento, tanto de possibilidades quanto de limites, sem que seja exigido à priori que o estudante execute estruturas de movimento pré-estabelecidas em um modo de cópia a ser reproduzida de igual maneira por todos. Dessa forma, as abordagens somáticas respondem ao espaço de pluralidade e diversidade. Em diálogo com Ginot:

A partir dos anos 70 , um conjunto de práticas paralelas, muito procuradas por bailarinos, encontrou um denominador comum: os 'métodos somáticos' ou 'somatics', conforme um termo proposto por Thomas Hanna (1995). Hanna propõe reunir sob essa denominação um conjunto de práticas que compartilhariam certos princípios, entre eles: a não-separação do corpo e da mente, evidentemente; mas também, o fato de levar em conta conhecimentos tanto objetivos, quanto subjetivos no que se refere à experiência do aluno (ou do cliente, do paciente) e do terapeuta. (Ginot, 2010, p. 02)

5 Na data de escrita deste texto o autor pertencia ao quadro de professores da UFSM. 
Com foco na experiência do estudante, as diversidades são respeitadas, assim como as construções e modos de mover e de se relacionar com o corpo que nos chegam junto com cada estudante. Nesse sentido, o Contato Improvisação se revela uma prática potente, ao colocar o enfoque sobre as percepções do praticante e sua relação com o movimento. Segundo Steve Paxton, por tratar-se mais de uma prática do que de uma performance, o Contato Improvisação "[...] tira os dançarinos da relação social em que eles são o centro. Não importa qual seja o sexo ou a condição do corpo, pois a técnica não é muito estilizada, nem muito rígida em sua fórmula" (2006, s/p).

Na disciplina de Expressão Corporal e Vocal III, os estudantes têm contato com conceitos da teoria/prática labaniana. Propomos a experimentação de exercícios que visam a compreensão de um corpo que se relacione com os fatores de movimento Espaço, Tempo, Peso e Fluência, propostos por Laban (1879-1958). A noção de Esforço se estabelece a partir da investigação de diferentes qualidades de movimentos e das atitudes interiores a eles relacionadas. Das combinações dos elementos supracitadas, adentramos na experimentação das oito ações básicas de esforço ou Ações Referenciais. Buscamos uma compreensão - corporal e intelectual - dessas ações, um certo "domínio do movimento". Para Laban,

O domínio do movimento [...] não tem valor apenas para o artista de palco, mas para todos nós, na medida em que todos nos vemos a braços, consciente ou inconscientemente, com a percepção e com a expressão. O indivíduo que aprendeu a relacionar-se com o Espaço, dominando-o fisicamente, tem Atenção. Aquele que detém o domínio de sua relação com o fator de esforço-Peso tem Intenção; e quando a pessoa se ajustou no Tempo, tem Decisão. (1978, p. 131)

O exercício consciente das ações corporais, portanto, extrapola a dimensão artística, elas são compreendidas e apreendidas como maneiras de trabalharmos a arte do movimento com diferentes grupos. Ao final da disciplina, é solicitado aos estudantes a criação de um "solo corporal". Essa composição deve unir os materiais experimentados ao longo do semestre com temas que os estudantes desejam pôr em contato com um público. A provocação posta é: sobre o que seu corpo quer falar? Tamanho o espanto quando os estudantes afirmam não terem tido, até aquele momento, a possibilidade de pensarem sobre o que seus corpos querem dizer. Os exercícios cênicos que haviam feito, diziam respeito a discursos de outras pessoas - em geral de dramaturgos consagrados - e, portanto, interessava uma "camuflagem" do corpo em prol de um personagem e não uma potencialidade dos discursos que seus corpos podem produzir. Em diálogo com Miller, "ao questionar a postura de atuação do artista cênico, podemos esperar que uma prática corporal declarada contemporânea habite um território coerente em relação aos acontecimentos mutáveis, breves e instáveis da nossa sociedade contemporânea [...]" (2012, p. 57), nesse sentido, quais conteúdos emergem dessas práticas?

À frente dessa disciplina nos últimos três anos, podemos presenciar a emersão de temáticas como: feminicídio, homofobia, racismo, preconceitos religiosos, liberdade, padrões de beleza, suicídio, depressão, ansiedade, solidão, bullying, entre outros. A partir dessas experiências, somos levados a refletir sobre as possibilidades de temas relacionados às diversidades adentrarem as práticas artísticas nos processos formativos. O reconhecimento de seus corpos e das camadas (culturais, emocionais, 
sociais, físicas) que os compõem transpostas sob a forma teatral, lançam olhares sobre si e possibilitam ao outro - espectador ou colega de turma - lidar com essas diferenças e especificidades; a diversidade do discurso passa ao campo da estética.

Outro paralelo pode ser posto em relação com as discussões propostas por Miler. Para a autora:

[...] a noção de técnica [...] não visa remeter ao adestramento condicionado e cristalizado. Ela é abordada como experiência da percepção e recurso para a construção do corpo próprio, um corpo disponível, à escuta, tal qual um processo de descobertas constantemente reformuladas, com respeito à individualidade do aluno artista. (Miller, 2012, p. 52, grifos da autora)

O trabalho técnico, portanto, busca uma ampliação de repertórios dos estudantes acerca das possibilidades de trabalho com o corpo, seja como artistas ou como futuros professores; o desenvolvimento de uma disponibilidade às sensações, percepções, estados e discursos que emanam desses corpos.

Não julgamos correto determinar padrões estéticos a serem estritamente seguidos, apesar de sabermos que a universidade, em muitos aspectos, ainda se mantém rígida e conservadora 6 . Tem sido, portanto, uma das preocupações das disciplinas instrumentalizar o estudante para que ele saiba reconhecer e trabalhar sobre sua estrutura corporal, o que significa, também, que ele tenha repertório argumentativo para justificar suas escolhas. A capacidade crítica e reflexiva é estimulada em relação às práticas desenvolvidas, bem como em relação aos diversos discursos corporais mais, ou menos, vigentes em cada espaço educacional ou artístico.

Um aspecto a ser destacado, apesar de parecer superado, é a dor entendida como sinônimo de um bom trabalho corporal. Tal aspecto segue operando em muitos espaços, revelando os equívocos que ainda se fazem presentes em relação às respostas do corpo nas práticas de criação. Segundo Sylvie Fortin:

\begin{abstract}
Meus estudos referentes às representações do corpo em dança demonstram que os usos do corpo dos artistas da dança profissional tendem a reproduzir o discurso dominante da dança teatral ocidental, que promove um ideal de corpo em que prevalecem os critérios estéticos de beleza, esbeltez, virtuosidade, devoção e ascetismo, tendo como efeito uma aceitação silenciosa dos já considerados normais dor e ferimento. (2011, p. 28)
\end{abstract}

Nesse sentido, parece necessário, também, questionar o quanto a formação dos estudantes é perpassada pelo diálogo - ou falta dele - entre as disciplinas e os docentes responsáveis por elas. Questionar, ainda, o quanto as diferentes abordagens presentes não apenas nas súmulas, mas, mais importante, nas ações pedagógicas dos docentes - são apresentadas de modo a possíveis relações e atravessamentos. Em muitos casos, diferentes práticas são apresentadas aos estudantes sem que uma relação entre elas seja esboçada ou problematizada. E ainda, algumas disciplinas operam na base da "tolerância" das diferenças, sem buscar os entendimentos sobre essas,

\footnotetext{
6 Mesmo no Curso de Teatro há relatos de estudantes avaliados negativamente em exercícios, por não imprimirem, por exemplo, maior "masculinidade" em sua movimentação, visto serem socialmente designados pertencentes ao sexo masculino.
} 
fazendo com que os estudantes sejam responsabilizados por assimilar as pluralidades de práticas, corpos e sujeitos.

Assim, nas disciplinas, lançamos atenção às especificidades dos estudantes, através do debate e do impulso à reflexão crítica sobre as práticas desenvolvidas, mas, sobretudo, por meio da postura do próprio professor frente aos conteúdos. Como professores, entendemos a necessidade de observar as questões específicas antes de realizar um trabalho, levando em consideração as características do coletivo no planejamento de cada aula. Defendemos que o professor se questione sobre como proceder para que o processo de ensino-aprendizagem do estudante não seja deixado de lado, mas que se respeitem suas condições corporais. Não nos parece admissível, em uma universidade pública que tem a acessibilidade como premissa, que o professor opte pela exclusão do estudante das práticas como única saída. Ainda que muitos professores não tenham repertório ou conhecimento para trabalhar com alunos que apresentam lesões passageiras ou mesmo permanentes, ou ainda pessoas com deficiência, é necessária uma postura de disponibilidade à reinvenção diária e sistemática de suas práticas ${ }^{7}$.

\title{
Corpos nas escolas
}

A escola, de maneira geral, é reconhecidamente um espaço de "institucionalização" dos corpos: uniformes, filas, sinais, cabeças baixas, respostas em coro, certo ou errado. Tenta, de forma falida, fazer com que um mundo de informações caiba no espaço de uma lousa, que é apagada de tempo em tempo, ainda que nem todos tenham conseguido copiar. As experiências dos sujeitos pouco ou nada importam como fonte de conhecimento, esses, universalmente válidos, foram previamente delimitados por uma "base" que indica o que deve ou não ser ensinado. O corpo é induzido a abdicar de suas expressões; visão e audição são os sentidos que importam a esse espaço.

\begin{abstract}
Na escola ou fora dela, o condicionamento da sensibilidade do corpo tem se adequado unicamente a reagir aos constantes choques provocados pelo excesso de estímulos e informações cotidianos, numa tendência a homogeneizar nosso comportamento, inibir o acesso à memória longa e ao compartilhamento de experiências e narrativas (Francelino, 2017, p. 139).
\end{abstract}

A aula de teatro, por sua vez, é reconhecidamente o espaço da expressão, do movimento, do barulho que "incomoda", dos gritos, empurrões, risadas, enfim, das manifestações de um corpo que passa de passivo para ativo na produção de um conhecimento que se dá no próprio corpo. Em que medida, entretanto, os trabalhos empreendidos nas disciplinas responsáveis pela formação desse professor de teatro o habilitam a reconhecer as singularidades do corpo de cada estudante e a operar como um mobilizador das capacidades expressivas de corpos em (trans)formação - crianças e adolescentes? Como trabalhar com esses corpos na escola sem a reprodução

\footnotetext{
7 À guisa de exemplo, citamos que já tivemos matriculado na disciplina Expressão Corporal e Vocal I um estudante surdo. Na primeira aula, cursando a disciplina pela segunda vez, o estudante informou que poderia ficar sem participar das aulas em que seriam trabalhados os conteúdos de voz. 0 aluno foi informado que ele não deveria ter tal preocupação, já que, o docente do conteúdo a ser desenvolvido deveria ajustar as aulas, organizando propostas que pudessem ser executadas por todos, sem exceção, respeitando as características individuais.
} 
de práticas desconectadas dos contextos em que habitam esses sujeitos ou sem visar unicamente a uma aquisição de habilidades técnicas que não nos parece ser o objetivo das práticas educativas em teatro? $\mathrm{E}$, ainda, de que maneira a aula de teatro pode potencializar de forma poética esses corpos, compreendendo-os como escrituras histórico-culturais e como sujeitos com seus modos próprios de se portarem no mundo?

Em "Jogos corporais em sala de aula", Nara Keiserman retrata um trabalho desenvolvido com jogos, sobre o qual aponta que:

Dentro do imenso repertório de Jogos Teatrais, há aqueles em que o Movimento é usado pelo aluno como principal meio de expressão, em que se pode dizer que é o corpo que fala. Estes jogos favorecem a aquisição e/ou aprimoramento de diferentes qualidades, referentes tanto a aspectos propriamente físicos, como outras de caráter social e mesmo psicológico (Keiserman, 2009, p. 221).

Nesse sentido, o trabalho corporal a ser desenvolvido na escola, necessitaria evocar a manutenção de um corpo que permaneça em contato com suas sensações e sentimentos, canalizando-as em expressão/movimento e, a partir da ampliação dos canais de percepção, despertar ou potencializar as capacidades imaginativas dos educandos. Conhecer-se e reconhecer-se; "[...] conhecer-se em ação: em ações rotineiras, em ações inusitadas, em ações propostas, em ações imprevistas, em ações exigidas, em ações improvisadas" (Azevedo, 2008, p. 279). Tornar o corpo disponível às relações, com o outro, com o mundo, consigo mesmo.

Ao discutirmos uma formação que se centra na "aquisição" de um corpo e não na "potencialização" desse, parece-nos que na formação desse educador há uma exclusão de corpos que destoam de um padrão, branco, heterossexual, cisgênero, magro, sem deficiências. Se o licenciando, em seu processo formativo, não for levado a questionar as imposições de modelos advindos de uma tradição tanto histórica (patriarcal, cristã, europeia) quanto de práticas teatrais convencionais dominantes (textocêntricas, miméticas, hierárquicas), poucas condições terá de desenvolver práticas artístico-pedagógicas próximas à cena contemporânea em que o discurso dos corpos se faz presente e potente.

Para além de se utilizar de histórias escritas há séculos em um processo de criação, porque não se aventurar a descobrir quais histórias estão impressas no corpo de seus educandos? Quais memórias, afetos, desejos, contradições, permeiam esses corpos e são silenciados pela escola, mesmo nas práticas artísticas que se propõem a ser espaços nos quais os sujeitos possam se colocar? Quais discursos constituem os corpos que se colocam em relação na sala de aula e como as práticas cênicas podem ser formativas ao investir em tais discursos, promovendo os estudantes de posições passivas, de corpos dóceis, a agentes ativos em seus contextos sociais?

Ao tratar do modo como as questões étnico-raciais, por exemplo, são tratadas na escola, Costa pontua:

Ainda frequente em muitas práticas pedagógicas, o termo folclore enquadra a cultura negra nas noções de exotismo e de inferioridade. Sob o viés do folclore, os saberes são moldados na ideia de primitividade, congelados no tempo e desprovidos de dinâmicas próprias das historicidades. [...] os discursos escolarizados estão repletos de simbolismos associando o povo negro à submissão, à servidão e à inferioridade. $(2017$, p. 100) 
Assim como um corpo negro, um corpo trans, afeminado, gordo, com deficiência, ao entrar em cena propõe uma leitura que transpassa qualquer tentativa de fabulação, representação ou ocultamento. Ele carrega uma dinâmica social, um imaginário, ele provoca, choca, incomoda. Como não levar em conta essas especificidades na escola? Quais enfrentamentos são necessários aos professores de teatro para romperem com o senso comum de que o teatro está na escola para "apresentar" histórias deslocadas dos sujeitos, com final feliz e uma "moral da história" a ser apreendida?

O teatro contemporâneo investe na crise da democracia ocidental, a questão dos gêneros, identidades e autenticidade. Ele se expõe a leituras que são geralmente políticas, pós-coloniais, queer, feministas; ele reinveste fontes literárias, cinematográficas, populares, folclóricas e aprofunda os saberes. Ele dialoga com a ciência, assume a forma de palestras. O teatro contemporâneo empresta, arranca, copia e cola, fazendo da colagem uma segunda natureza. Ele tenta reconquistar o sagrado, procura fazer comunidade, criar comum, decifrar seu público tomando-o como um objeto, encenando-o. É um teatro que às vezes recusa o rótulo de teatro, renuncia aos artifícios do palco ou exacerba o espetacular até lhe dar uma função crítica. (Mill, 2017, p. 60) ${ }^{8}$

É comum ouvirmos que as escolas cobram as apresentações teatrais em eventos ou como conclusão do ano letivo e entendemos que o contato com o público é uma etapa formativa da linguagem teatral, o momento em que o discurso cênico é comunicado, em que se põe em relação aquele que faz e aquele que vê. Parece-nos fundamental que esses momentos sejam questionadores, que, impulsionados pela cena teatral contemporânea, tragam as vivências, desejos e indagações que atravessam os corpos dos estudantes. Que sejam essas as oportunidades de questionarmos os padrões corporais impostos, os estereótipos socialmente construídos em torno das figuras "desviantes", os modos de fazer teatro tradicionalmente reproduzidos na escola.

Desejamos que os licenciados em teatro entendam o espaço potencialmente subversivo da arte teatral e lutem pela instauração de práticas pedagógico-teatrais que celebrem as diversidades e não as inviabilizem em função de um discurso que se diz "sem partido", mas que pretende homogeneizar e reprimir os corpos.

\section{Provocações finais}

A reflexão crítica aliada à prática corporal no processo formativo do educador-artista, parece-nos imprescindível, não só pensando na atuação cênica, mas, especialmente, no profissional que vai compartilhar espaços com outros sujeitos em processos de ensino-aprendizagem-criação.

Ainda que o trabalho na escola não tenha como objetivo a formação do ator, é necessário que o futuro professor de teatro reconheça que diferentes estéticas estão relacionadas a um modo de operar do corpo em cena com suas exigências específicas e que existem outros corpos/discursos a serem potencializados.

\footnotetext{
8 "Le théâtre contemporain investit la crise de la démocratie occidentale, la question des genres, des identités et de l'authenticité. II s'expose à des lectures couramment politiques, postcoloniales, queer, féministes; il réinvestit les sources littéraires, filmiques, populaires, folkloriques, et approfondit des savoirs. II dialogue avec la science, prend la forme de conférences. Le théâtre contemporain emprunte, pille, copie et colle, faisant du collage une deuxième nature. II tente une reconquête du sacré, cherche à faire communauté, à créer du commun, à déchifrer son public en le prenant comme objet, en le mettant en scène. C'est un théâtre qui refuse parfois l'étiquette de théâtre, renonce aux artifices de la scène ou exacerbe le spectaculaire jusqu'à lui donner une fonction critique". (Tradução nossa)
} 
Parece que um dos elementos centrais no trabalho do professor de teatro é o reconhecimento das estruturas corporais, das singularidades de cada corpo, seguido do conhecimento específico de técnicas e práticas que o auxiliem a desenvolver objetivos específicos no trabalho das artes cênicas. Tal postura indica um olhar apurado aos necessários ajustamentos em cada contexto: escola, grupo de atores, companhia, entre outros.

Essa observação atenta, estimulada no processo formativo, possibilita que o futuro professor perceba as diversidades corporais dos estudantes na escola - corpos em formação. A cada planejamento, o professor tem a possibilidade de desenvolver o importante exercício de compreensão de suas práticas em relação às necessidades e possibilidades dos estudantes. Reconhecendo as implicações de cada prática, torna-se responsável pelos ajustamentos e reorganizações coerentes a cada grupo.

Fazer com que as práticas educativas em teatro sejam contaminadas pela cena contemporânea, em que os corpos forjam espaços de discurso, em que as diversidades emerjem como potentes mobilizadores de outras leituras de mundo. Uma prática cênica em que as diversidades reclamam seu espaço, não sendo contidas pela estrutura institucionalizada, não havendo uma contenção dos corpos, mas uma vazão de discursos poéticos, políticos, estéticos. De seu lugar de organizador dos tempos e espaços artístico-pedagógicos, que o professor possa promover fissuras que convoquem os corpos dos estudantes a expressarem suas individualidades, assumindo a sala de aula como espaço de partilha e convivência entre diversos.

\section{Referências}

AZEVEDO, Sônia Machado de. O papel do corpo no corpo do ator. $2^{\underline{a}}$ ed. São Paulo: Perspectiva: 2008.

BARBA, Eugenio; SAVARESE, Nicola. A arte secreta do ator: dicionário de antropologia teatral. São Paulo: Hucitec, 1995.

BOAL, Augusto. Jogos para atores e não atores. 15a ed. Rio de Janeiro: Civilização Brasileira, 2012.

BOAL, Augusto. Teatro do Oprimido e Outras Poéticas Políticas. 4a ed. Rio de Janeiro: Civilização Brasileira, 1980.

COSTA, Alberto Roberto. Ato de criação e processos de docilização e resistência. In: MUNIZ, Mariana Lima; CRUVINEL, Tiago (Orgs.). Pedagogia das Artes Cênicas: criatividade e criação. Curitiba: Editora CRV, 2017. p. 93-106.

FELDENKRAIS, Moshe. Consciência pelo movimento. [Tradução de Daisy A. C. Souza]. São Paulo: Summus, 1977.

FORTIN, Sylvie. Nem do Lado Direito, nem do Avesso: o artista e suas modalidades de experiências de si e do mundo. In: WOSNIAK, Cristiane; MARINHO, Nirvana (Org.). O Avesso do Avesso do Corpo: Educação somática como práxis. Joinville: Nova Letra, 2011, p. 25-42. 
FRANCELINO, Elton Mendes. Po-ética, o corpo como território da experiência. In: MUNIZ, Mariana Lima; CRUVINEL, Tiago (orgs.). Pedagogia das Artes Cênicas: criatividade e criação. Curitiba: Editora CRV, 2017. p. 137-148.

GINOT, Isabelle. Para uma epistemologia das técnicas de educação somática. O Percevejo. Rio de Janeiro, v. 2, n. 2, p. 01-17, 2010.

JOROSKY, Nara Helena. Dança educativa no ambiente escolar a luz da proposta de Rudolf Laban. Revista Hórus. Vol. 4, n. 1. p. 156-164. São Paulo: Faculdade Estágio de Sá de Ourinhos, 2010.

KEISERMAN, Nara. Jogos corporais na sala de aula. In: TELLES, Narciso; FLORENTINO, Adilson (Orgs). Cartografias do ensino do teatro. Uberlândia: EDUFU, 2009. p. 221-231.

LABAN, Rudolf. Domínio do movimento. 5a ed. [Tradução: Anna Maria Barros De Vecchi e Maria Sílvia Mourão Netto]. São Paulo: Summus, 1978.

LE BRETON, David. A sociologia do corpo. 3ạ ed. [Tradução de Sônia M.S. Fuhrmann] Petrópolis, RJ: Vozes, 2009.

LEHMANN, Hans-Thies. O Teatro Pós Dramático. 2ª ed. [Tradução de Pedro Süssekind] São Paulo: Cosac \& Naify, 2011.

MILL, Jessie. Le théâtre qui nous manque: le théâtre québécois engendre-t-il encore des « avant-gardes » ? Liberté. Numéro 314, Hiver, p. 60-62, 2017.

MILLER, Jussara. Qual é o corpo que dança?: dança e educação somática para adultos e crianças. São Paulo: Summus, 2012.

PAXTON, Steve. A definition. [1978/79]. Contact Improvisation Source Book: collected writings and graphics from Contact Quarterly dance journal 1975-1992. Massachusetts: Contact Editions, p. 37-38, 1997.

PAXTON, Steve. Corpos em liberdade (depoimento). Revista E. N. 108, maio 2006. Disponível em <http://www.sescsp.org.br/online/artigo/3145_DEPOIMENTOS\#/tagcloud=lista $>$. Acesso em: 21 set. 2018. 